\title{
Hyperbilirubinemia as a Post-Sphincterotomy Bleeding Risk during Endoscopic Retrograde Cholangio-Pancreatography (ERCP) Procedure in Normal Hemostasis Profile Patients
}

\author{
C. Rinaldi A. Lesmana ${ }^{1,2 *}$, Waldemar Simandjuntak ${ }^{1}$, Laurentius A. Lesmana ${ }^{1}$ \\ ${ }^{1}$ Digestive Disease \& GI Oncology Center, Medistra Hospital, Jakarta \\ ${ }^{2}$ Hepatobiliary Division, Department of Medicine, Cipto Mangunkusumo Hospital, Medical Faculty University of Indonesia
}

Received: October 31,2016; Accepted: November 11, 2016; Published: November 28, 2016

*Corresponding author: C. Rinaldi A. Lesmana, Digestive Disease \& GI Oncology Center, Medistra Hospital, Jakarta and Hepatobiliary Division, Department of Medicine, Cipto Mangunkusumo Hospital, Medical Faculty University of Indonesia, Email: medicaldr2001id@yahoo.com

\begin{abstract}
Aim: To find out whether high bilirubin level is an important risk factor for immediate post-sphincterotomy bleeding during endoscopic retrograde cholangio-pancreatography (ERCP) even in normal hemostasis profile patients.

Methods: A retrospective analysis was performed from ERCP clinical database at Digestive Disease \& GI Oncology Center, Medistra Hospital within 4 years period (January 2012- May 2016). Data were collected from patients with obstructive jaundice who are indicated for ERCP procedure. High bilirubin level is defined when the patient's bilirubin level $10 \mathrm{mg} / \mathrm{dL}$ and above. All patients who underwent ERCP procedure don't have abnormal hemostasis. No histories of oralanticoagulant or patients who take oral-anticoagulant medicine have stopped the medicine at least 5 days before the procedures. Patients with hyperbilirubinemia due to pre and intra-hepatic causes, liver cirrhosis or liver cancer were excluded. Data analysis was performed using SPSS ver. 16.
\end{abstract}

Results: 124 naïve patients (70 men and 54 women) were eligible for data analysis. The major reason for ERCP procedures was dominated by non-malignant condition (88\%) such as choledocolithiasis, Mirrizi syndrome, benign hilar stricture, and post operative bile leak. Bleeding complication was recorded in 30 patients and it was able to be managed endoscopically during ERCP procedures. Bleeding complication was noted in most patients who didn't have severe hyperbilirubinemia.

Conclusion: Our study showed that high level of bilirubin per se might not a risk factor for immediate post-sphincterotomy bleeding but may be more due to anatomical factor.

Keywords: Hyperbilirubinemia; Sphincterotomy; Bleeding; ERCP; Normal hemostasis

\section{Background}

Endoscopic retrograde cholangio-pancreatography (ERCP) is one of the challenging endoscopic procedures in gastroenterology field due to its risk and complications $[1,2]$. Instead of the procedure's risk, patient's clinical conditions also contribute in the development of complications after procedure, such as age, heart and lung condition, electrolyte imbalance, advanced liver disease, and liver coagulopathy. Obstructive jaundice, especially in patients with high bilirubin level can be more challenging due to the risks of infection and bleeding [3, 4]. Hyperbilirubinemia can lead to hemostasis impairment due to poor absorption of vitamin K. Bacterial translocation is also play a major role in hemostasis disturbance due to inflammation, septic complication, and disseminated intravascular coagulation (DIC) [5]. Endoscopic sphincterotomy is a common procedure in ERCP where it has a potential risk for bleeding complication, even in patients with normal blood coagulation [6]. Until now, there is still lack of data about immediate bleeding risk in severe hyperbilirubinemia patients due to post-hepatic obstructive jaundice who underwent ERCP procedure.

\section{Patients and Method}

A retrospective analysis was performed from ERCP clinical database at Digestive Disease \& GI Oncology Center, Medistra Hospitalwithin 4 year's period (January 2012- May 2016). Medistra hospital is the most referred private hospital for patients with hepatopancreatobiliary disorders. ERCP procedures were performed by three experienced gastroenterologists, where two consultants has been experienced in ERCP procedures more than 30 years and another consultant has been experienced more than 8 years with large number of patients. Data were collected from patients with obstructive jaundice who need (clearly indicated) ERCP procedure. High bilirubin level is defined when the patient's bilirubin level $10 \mathrm{mg} / \mathrm{dL}$ and above. All patients who underwent ERCP procedure with hemostasis impairment (prolonged INR $\geq 1.4$ based on our hematology association policy to performed intervention procedure) were excluded. No histories of NSAID, oral-anticoagulant or patients who take oralanticoagulant medicine have stopped the medicine at least 5 days before the procedures. Patients with hyperbilirubinemia due to pre and intra-hepatic causes, liver cirrhosis or liver cancer were 
excluded. Data analysis (descriptive and logistic regression) was performed using SPSS ver. 16. The study has been approved by the hospital ethic committee.

\section{Results}

Of 669 patients in patient's database who underwent ERCP procedures during this period, there were 147 naïve patients because most of them underwent repeated ERCP due to recurrent CBD stones or need for plastic stent exchange. From 147 patients, there were 124 naïve patients ( 70 men and 54 women) who underwent ERCP and sphincterotomy (table 1). High bilirubin levels were noted in 26 (21\%) patients.The major reason for ERCP procedures was dominated by non-malignant condition (88\%) such as choledocolithiasis, Mirrizi syndrome, benign hilar stricture, and postoperative bile leak (table 2).

Immediate bleeding was recorded in $30(24.2 \%)$ patients and was able to be managed endoscopically during ERCP procedures. Logistic regression analysis showed that high bilirubin level per se is not a significance post-sphincterotomy bleeding risk factor in patients who underwent ERCP procedure $(p .881)$ with the OR $0.925(0.333-2.570$, CI 95\%). Other possible risk factors such as cholangitis and the presence of diverticle also being analyzed for adjusted OR and it showed no statistical significance (Table 3).

\section{Discussion}

To our knowledge, this is the first retrospective study with a quite number of patients in Asia looking at hyperbilirubinemia as a bleeding risk factor during ERCP and sphincterotomy procedure in normal hemostasis profile patients. Studies have shown some risks of post-sphincterotomy bleeding incidence mostly due to cholangitis before ERCP, low volume centre, hemostasis disorders, advanced liver cirrhosis, precut sphincterotomy, CBD stone, and the use of prolonged oral anti-coagulant $[7,8]$. High bilirubin level in patients with obstructive jaundice plays an important role for a risk of bleeding due to vitamin K deficiency. There is a reduction of vitamin $\mathrm{K}$ absorption due to cholestasis

Table 1: Patient's characteristic $(\mathrm{N}=124)$

\begin{tabular}{|c|c|c|c|}
\hline & N (\%) & Median (Range) \\
\hline \multirow{2}{*}{ Sex } & Female & $54(56.5)$ & \\
\hline & Male & $70(43.5)$ & \\
\hline Age (years) & & & $59(21-98)$ \\
\hline Total bilirubin (mg/dL) & & & $3.08(0.01-24.16)$ \\
\hline Platelet count (/ul) & & & $\begin{array}{l}266.500(138.000- \\
807.000)\end{array}$ \\
\hline Prothrombin Time (PT) & & & $12.9(9.20-16.70)$ \\
\hline $\begin{array}{c}\text { Partial Thromboplastin } \\
\text { Time (aPTT) }\end{array}$ & & & $32.0(12.80-58.00)$ \\
\hline $\begin{array}{c}\text { International Normalized } \\
\text { Ratio (INR) }\end{array}$ & & & $1.07(0.8-1.40)$ \\
\hline
\end{tabular}

Table 2: Etiology of the diseases

\begin{tabular}{|c|c|}
\hline Etiology & N (\%) \\
\hline Choledocolithiasis & $100(80.6)$ \\
\hline Pancreatic cancer & $4(3.2)$ \\
\hline Benign biliary stricture & $4(3.2)$ \\
\hline Mirrizi syndrome & $3(2.4)$ \\
\hline CBD mass & $3(2.4)$ \\
\hline Cholangiocarcinoma & $3(2.4)$ \\
\hline Klatskin tumor & $2(1.6)$ \\
\hline Liver cancer* & $2(1.6)$ \\
\hline Bile leak & $2(1.6)$ \\
\hline Ampullary cancer & $1(0.8)$ \\
\hline
\end{tabular}

Table 3: Bleeding Risk Factors during ERCP Procedure

\begin{tabular}{|c|c|c|c|c|}
\hline \multicolumn{2}{|c|}{ Variables } & \multirow{2}{*}{$\begin{array}{c}\begin{array}{c}\text { No } \\
\text { Bleeding }\end{array} \\
74\end{array}$} & \multirow{2}{*}{\begin{tabular}{c|} 
Bleeding \\
24
\end{tabular}} & \multirow{2}{*}{$\begin{array}{c}\boldsymbol{p} \text { (with adjusted } \mathbf{0 R}) \\
.699\end{array}$} \\
\hline \multirow{2}{*}{ Bilirubin } & Low & & & \\
\hline & High & 20 & 6 & OR $0.809(0.276-2.368)$ \\
\hline \multirow{2}{*}{ Diverticle } & Yes & 27 & 7 & .482 \\
\hline & No & 67 & 23 & OR $0.699(0.258-1.896)$ \\
\hline \multirow{2}{*}{ Cholangitis } & Yes & 19 & 7 & .603 \\
\hline & No & 75 & 23 & OR $1.311(0.472-3.640)$ \\
\hline
\end{tabular}

condition and the patients might have the hemorrhagic diathesis $[9,10]$. To our knowledge, there are only two previous studies showing that high bilirubin level is an independent risk factor in obstructive jaundice patients who underwent intervention procedures; however in one study the sample size was too small and in another study patients with decompensated liver cirrhosis and the use of anti-platelet before sphincterotomy were included $[11,12]$. In our study the population is more homogenous and it might be the reason of different finding. The study population between two previous studies and our study might not be relevant, but theoretically it doesn't change the risk of hyperbilirubinemia in bleeding complication.

Our study revealed that prevalence of immediate bleeding complication during ERCP procedure is almost similar, as it has been reported in the literature [6]. However, this complication is happened mostly in patients with low bilirubin level, supporting the fact that anatomical factor (difficult papilla positioning) and extensive sphincterotomy might be the most important risk factors for immediate post-sphincterotomy bleeding. Prolonged cholestasis in our patients due to patient's reluctant to undergo direct ERCP procedure, predominantly patients with CBD stones and dilated CBD or previously have been admitted at another hospital without any intervention might become another reasons. In our study, only two patients who underwent precut sphincterotomy, suggesting this would not interfere the 
results of the study. Stopping oral-anticoagulant therapy as well as hemostasis corrections before ERCP are important factors to prevent bleeding complication even though sometimes it could not be avoided. The combination of endoscopic sphincterotomy and balloon sphincteroplasty is a better option in patients who would undergo ERCP not only with history of oral-anticoagulant or anti-platelet therapy, but also in patients with advanced liver disease $[13,14]$.

This study has several limitations. First, it was designed as a retrospective study; however our center is the most referred private hospital for ERCP procedures. Second, we didn't analyze between malignant and non-malignant group due to most of our patients suffered from CBD stones.

In conclusion, our study showed that high level of bilirubin per se is not a risk factor for post-sphincterotomy bleeding but may be more due to anatomical factor (positioning the papilla due to individual ampulla). A prospective and randomized study is needed to confirm this finding.

\section{References}

1. Szary N, Al-Kawas FH. Complications of endoscopic retrograde cholangiopancreatography: How to avoid and manage them. Gastroenterol \&Hepatol. 2013;9(8):496-504.

2. Andriulli A, Loperfido S, Napolitano G, Niro G, Valvano MR, Spirito F, et al. Incidence rates of post-ERCP complications: A systematic survey of prospective studies. Am J Gastroenterol. 2007;102(8):1781-1788.

3. Travis AC, Pievsky D, Saltzman JR. Endoscopy in the Elderly. Am J Gastroenterol. 2012;107:1495-1501. doi: 10.1038/ajg.2012.246.

4. Adler DG, Haseeb A, Francis G, Kistler A, Kaplan J, Ghumman SS, et al. Efficacy and safety of therapeutic ERCP in patients with cirrhosis: a large multicenter study. Gastrointest Endosc 2016;83(2):353359. doi: $10.1016 /$ j.gie.2015.08.022.

5. Papadopoulos V, Filippou D, Manolis E, Mimidis K. Haemostasis impairment in patients with obstructive jaundice. J Gastrointestin Liver Dis. 2007;16(2):177-186.

6. Ferreira LEVVC, Baron TH. Post-sphincterotomy bleeding: who, what, when, and how. Am J Gastroenterol. 2007;102(12):2850-2858.

7. Li DM, Zhao J, Zhao Q, Qin H, Wang B, Li RX, et al. Safety and efficacy of endoscopic retrograde cholangiopancreatography for common bile duct stones in liver cirrhotic patients. J HuazhongUnivSciTechnolog Med Sci. 2014;34(4):612-615. doi: 10.1007/s11596-014-1325-X.

8. Wang P, Li ZS, Liu F, Ren X, Lu NH, Fan ZN, et al. Risk factors for ERCP-related complications: A prospective multicenter study. Am J Gastroenterol. 2009;104(1):31-40. doi: 10.1038/ajg.2008.5.

9. Constantin T. Jaundice obstructive syndrome. Curr Health Sci J. 2011;37(2):96-100.

10. Wang L, Yu WF. Obstructive jaundice and perioperative management ActaAnaesthesiologicaTaiwanica. 2014;52(1):22-29. doi: 10.1016/j. aat.2014.03.002.

11. Irabor DO. The risk of impaired coagulation in surgical jaundice: an analysis of routine parameters. SurgSci. 2012;3(3):116-119.

12. Lee MH, Tsou YK, Lin CH, Lee CS, Liu NJ, Sung KF, et al. Predictors of re-bleeding after endoscopic hemostasis for delayed post-endoscopic sphincterotomy bleeding. World J Gastroenterol. 2016;22(11):31963201. doi: 10.3748/wjg.v22.i11.3196.

13. Guo SB, Meng H, Duan ZJ, Li CY. Small sphincterotomy combined with endoscopic papillary large balloon dilatation vs sphincterotomy alone for removal of common bile duct stones. World J Gastroenterol. 2014;20(47):17962-17969.

14. Hwang JC, Kim JH, Lim SG, Kim SS, Shin SJ, Lee KM, et al. Endoscopic large-balloon dilatation alone versus endoscopic sphincterotomy plus large-balloon dilatation for the treatment of large bile duct stones. BMC Gastroenterol. 2013;13:15. DOI: 10.1186/1471-230X-13-15. 